\title{
Functionalization of mono- and bimetallic MIL-100(Al,Fe) MOFs by ethylenediamine: post-functionalization, Brønsted acido-basicity and unique $\mathrm{CO}_{2}$ sorption behaviour
}

\author{
Timothy Steenhaut, ${ }^{\text {*a }}$ Luca Fusaro, ${ }^{\mathrm{b}}$ Koen Robeyns, ${ }^{\mathrm{a}}$ Séraphin Lacour, ${ }^{\mathrm{a}}$ Xiao Li, ${ }^{\mathrm{a}}$ Julien G. Mahy, ${ }^{\mathrm{a}}$ \\ Véronique Louppe, ${ }^{a}$ Nicolas Grégoire, ${ }^{a}$ Gabriella Barozzino-Consiglio, ${ }^{a}$ Jean-François Statsyns, ${ }^{a}$ \\ Carmela Aprile, ${ }^{\text {}}$ Yaroslav Filinchuk*a and Sophie Hermans*a \\ ${ }^{\text {a }}$ Institute of Condensed Matter and Nanosciences (IMCN), UCLouvain, Place Louis Pasteur 1/L4.01.03, 1348 Lou- \\ vain-la-Neuve, Belgium \\ ${ }^{\mathrm{b}}$ Namur Institute of Structured Matter (NISM), UNamur, Rue de Bruxelles 61, B-50oo Namur, Belgium
}

\begin{abstract}
The metal sites of MIL-10o(Fe), MIL-10o(Fe,Al) and MIL-10o(Al) MOFs were decorated with ethylenediamine (EN). Interestingly, the Al-containing MOFs presented hierachized porosity, and their structural integrity was maintained upon functionalization. Solution and solid-state NMR confirmed the grafting efficiency in the case of MIL-10o(Al) and the presence of a free amine group. It was shown that MIL-10o(Al) can be functionalized by only one EN molecule by trimeric $\mathrm{Al}_{3} \mathrm{O}$ cluster unit, whereas the two other aluminium sites are occupied by an hydroxyl and a water molecule. The $-\mathrm{NH}_{2}$ sites of the grafted ethylenediamine can be used for further post-functionalization through amine chemistry and is responsible for basicity of the functionalized material. Furthermore, the presence of coordinated water molecules on the Al-MOF is responsible for simultaneous Brønsted acidity and for a unique carbon dioxyde sorption mecanism, that distinguishes this material from its iron and chromium couterparts.
\end{abstract}

\section{Introduction}

Metal-organic frameworks (MOFs) are porous coordination polymers that hold great promise in fields such as the capture of greenhouse gases, ${ }^{1}$ including carbon dioxide, ${ }^{2}$ gas storage for energy applications $\left(\mathrm{H}_{2}, \mathrm{CH}_{4}\right), 3$ drug delivery, ${ }^{4}$ sensing 5 and catalysis. To improve $\mathrm{CO}_{2}$ sorption in MOFs, functionalization of those materials with basic functions, ${ }^{6}$ and more specifically amines, ${ }^{7}$ is very efficient. Such functions are also very valuable tools for post-functionalisation purposes relying on the rich chemistry of amines, ${ }^{8}$ as well as for base-promoted catalysis. ${ }^{9}$ The incorporation of amines is usually carried out by using modified ligands to build the MOF. However, amine-bearing ligands are often more expensive. One alternative is to functionalize metal sites in MOFs with cheap ethylenediamine (EN), which uses one $-\mathrm{NH}_{2}$ site as anchor to the MOF's structure, leaving a second pendant amine site available..$^{10,11,12,13}$ The chromium-based MIL-10o $(\mathrm{Cr})$, built using the benzene1,3,5-tricarboxylate (also called trimesate, BTC $^{-}$) ligand, is a MOF that has shown great promise in this perspective. ${ }^{14,15,16}$ However, this chromium-based MOF is not likely to be used in large-scale industrial applications due to environmental and health concerns. ${ }^{17}$ This is because of strong regulations concerning chromium, which is highly hazardous in its +VI oxidation state..$^{18}$ Nevertheless, the MIL-10o structure remains very interesting for functionali- zation purposes because its large pores ( 25 and 29 Å diameter) allow for introducing functional units while still maintaining high surface areas. ${ }^{19,20}$ For this reason, we investigated the possibility to functionalize MIL-10o(Al) and MIL-10o(Fe), which are based on widely available (and thus cheap) and less problematic metals, as well as their bimetallic counterpart MIL-10o(Fe,Al). Furthermore, because it is based on the lightest metal that can commonly attain the +III oxidation state, MIL-10o(Al) is more promising for gravimetric gas sorption applications owing to its lower density.

\section{Experimental}

\section{A. Instruments}

Powder diffraction data were collected on a STOE STADI $P$ Combi diffractometer using either MoK $\alpha$ radiation (50 $\mathrm{kV}, 40 \mathrm{~mA}$ ) or $\mathrm{CuK}_{\alpha}$ radiation $(40 \mathrm{kV}, 40 \mathrm{~mA}$ ) (graphite primary monochromator). The diffracted beam was recorded on a DECTRIS MYTHEN 1 K strip detector. Samples were loaded in $0.7 \mathrm{~mm}$ diameter capillaries, aligned to the geometric center of the diffractometer and measured in transmission, with independent 2-theta movement.

Infrared spectra were recorded in the $4000-370 \mathrm{~cm}^{-1}$ range on a Bruker Alpha spectrometer equipped with a Platinum ATR module (diamond crystal) housed in an argon-filled glovebox. 
TGA measurements of the MOFs were performed on a Mettler Toledo TGA/DSC ${ }^{3+}$ system equipped with a sample robot. The air flow was of $100 \mathrm{ml} / \mathrm{min}$. An initial isotherm at $27^{\circ} \mathrm{C}$ was applied during 15 minutes before heating the sample up to $900^{\circ} \mathrm{C}$ at a rate of $10 \mathrm{~K} / \mathrm{min}$. TGA-MS was done by coupling a ThermoStarTM GSD 301 T mass spectrometer to the outlet of the TGA oven.

Nitrogen sorption isotherms were measured at $77 \mathrm{~K}$ using a Micromeritics ASAP2020 equipment. All samples were activated at $200^{\circ} \mathrm{C}$ or $150^{\circ} \mathrm{C}$ (depending on the sample) under dynamic vacuum for $10 \mathrm{~h}$ prior to analysis.

Solution-state ${ }^{1} \mathrm{H}$ NMR spectra were recorded at room temperature (296 K) on a Bruker Avance II 300 spectrometer operating at 300.1 MHz. Experiments were run under TopSpin program (3.2 version, Bruker) using a BBFO $\left\{{ }^{1} \mathrm{H}\right.$, $\mathrm{X}\}$ probehead equipped with a $\mathrm{z}$-gradient coil. ${ }^{1} \mathrm{H}$ chemical shifts are reported in parts per million ( $\mathrm{ppm})$ and referenced to the residual signal of DMSO- $d_{5}(\delta 2.50 \mathrm{ppm})$. Samples were prepared by putting an appropriate amount of solid in a glass test tube equipped with a ground glass joint. For activation, a glass stopcock, connected to a vacuum supply (via a Schlenk line), was adapted on the test tube and heating was applied using an oil bath. About $0.5 \mathrm{ml}$ $\mathrm{D}_{2} \mathrm{SO}_{4}$ was then added to the sample by using a glass pipette, followed by an appropriate amount (enough to obtain a clear solution after heating) of DMSO- $d_{6}$. The test tube was then sealed with a glass stopper and the mixture was heated using a heat gun until a clear solution was obtained (in case of difficult solubilisation, some DMSO- $d_{6}$ was added and the mixture was heated again to obtain a clear solution). The solution was then cooled and transferred into a $5 \mathrm{~mm}$ thin-walled precision NMR sample tube for analysis. Note: The added volume of DMSO- $d_{6}$ is variable depending on the sample to dissolve. The total quantity needed to achieve complete dissolution is dependent on the nature of the sample (portions of $\sim 0.5 \mathrm{ml}$ were added until a clear solution was obtained). This results in variable $\mathrm{D}_{2} \mathrm{SO}_{4} / \mathrm{DMSO}$ ratios for each analyzed sample and in slight shifts of peak positions in the ${ }^{1} \mathrm{H}$ NMR spectra but does not affect the quantification of the $\mathrm{EN} / \mathrm{H}_{3} \mathrm{BTC}$ ratio.

Solid-state ${ }^{13} \mathrm{C}$ and ${ }^{15} \mathrm{~N}$ Cross-Polarization (CP) Magic Angle Spinning (MAS) NMR spectra were acquired at room temperature, on a Bruker Avance-50o NMR spectrometer operating at $11.7 \mathrm{~T}\left(125.8 \mathrm{MHz}\right.$ for ${ }_{13} \mathrm{C}$ and $50.6 \mathrm{MHz}$ for ${ }_{15} \mathrm{~N}$ ) and equipped with a $4 \mathrm{~mm}$ CP-MAS Bruker probe. ${ }^{13 \mathrm{C}}$ CP-MAS spectra were recorded using a contact time of 2 ms, a spinning rate of $10 \mathrm{KHz}$, relaxation delay of $5 \mathrm{~s}$ and 1000 scans. ${ }^{15} \mathrm{~N}$ CP-MAS spectrum was recorded using a contact time of $2 \mathrm{~ms}$, a spinning rate of $8 \mathrm{KHz}$, relaxation delay of $10 \mathrm{~s}$ and 92000 scans. The processing comprised exponential multiplication of the free induction decay with a line broadening factor of $10 \mathrm{~Hz}$, zero filling prior to Fourier transform, phase, and baseline corrections. Chemical shifts scales were referenced externally to solid adamantane $\left({ }^{13} \mathrm{C}: 38.68 \mathrm{ppm}\right)$ and ammonium chloride $\left({ }^{15} \mathrm{~N}: 39 \cdot 3\right.$ ppm). ${ }^{1,2}$ Solid-state ${ }^{27} \mathrm{Al}$ MAS NMR spectra were acquired at room temperature, on a $400 \mathrm{MHz}$ Varian VNMRS spectrometer operating at $9.4 \mathrm{~T}\left(104.2 \mathrm{MHz}\right.$ for $\left.{ }^{27} \mathrm{Al}\right)$ and equipped with a $4 \mathrm{~mm}$ Chemagnetics T3 probe. MAS spectra were recorded using a spinning rate of $8 \mathrm{kHz}$. Processing comprised manual baseline correction. Chemical shifts were referenced externally to aluminium nitrate in $\mathrm{H}_{2} \mathrm{O}$ ( ${ }^{27} \mathrm{Al}$ : $\left.0.0 \mathrm{ppm}\right)$. Note: The MIL-10o(Al) sample that was used for solid-state NMR investigations was first activated and then rehydrated by prolonged exposure to air for several days.

Solid-state UV-vis measurements of bromothymol blue impregnated samples were performed on a Shimadzu UV3600 Plus UV-Vis-NIR spectrometer equipped with a Harrick single-beam Praying Mantis Diffuse Reflectance collection system. A Spectralon ${ }^{\circledR}$ Diffuse Reflectance Standard was used to measure the background spectra.

Solution-state UV-vis measurements of the ninhydrin tests were collected on a $1700 \mathrm{UV} /$ visible spectrophotometer from Shimadzu.

Volumetric carbon dioxide sorption experiments were performed on an IMI-HTP Sievert's apparatus from Hiden Isochema. For the experiments, about $100 \mathrm{mg}$ of sample was used and activated under vacuum at $100^{\circ} \mathrm{C}$ or $200^{\circ} \mathrm{C}$ before sorption experiments.

Gravimetric sorption experiments were performed on a Mettler Toledo TGA/DSC ${ }^{3+}$ system. For each experiment, the sample was activated in situ in the thermogravimetric analyzer by heating $(10 \mathrm{~K} / \mathrm{min})$ to $100^{\circ} \mathrm{C}$ ( $2 \mathrm{~h}$ isotherm) and cooling back to $25^{\circ} \mathrm{C}(10 \mathrm{~K} / \mathrm{min})$ and maintaining this temperature for $90 \mathrm{~min}$, all those operations being performed under helium (100 $\mathrm{ml} / \mathrm{min})$. The adsorption/desorption cycles were realized by switching gas fluxes every 6o min from helium (100 $\mathrm{ml} / \mathrm{min})$ to carbon dioxide $(100 \mathrm{ml} / \mathrm{min}$ ) and vice-versa at a constant temperature of $25^{\circ} \mathrm{C}$.

\section{B. Chemicals}

Trimesic acid (98\%), heptane (99\%), thiophosgene $(85 \%)$, iodomethane $(99 \%$, stabilized), dry ether $(99.5 \%$, extra dry), triethylamine (99\%) and toluene (99.85\%, Extra Dry, AcroSeal $^{\circledR}$ ) were purchased from Acros Organics. Denaturated ethanol (Technisolv, 99\%), dimethylformamide (HiPerSolv, CHROMANORM), methanol (HiPerSolv, CHROMANORM), DCM (HiPerSolv, CHROMANORM), pentane (HiPerSolv), hexane (HiPerSolv, CHROMANORM), sodium hydroxide pellets, $\mathrm{HCl} 37 \%$ (AnalaR, NORMAPUR) and ninhydrin (AnalaR, NORMAPUR ${ }^{\circledast}$ ACS, Reag. Ph. Eur., for analysis) were purchased from VWR Chemicals. $\mathrm{D}_{2} \mathrm{SO}_{4}$ and DMSO-d $d_{6}$ were purchased from Euriso-top. Ethylenediamine (>99.5\%), boron trifluoride diethyletherate, aluminium chloride (98\%) and hexylamine (99\%) were purchased from Merck. Bromothymol blue was purchased from Alfa Aesar. All chemicals were used as received.

\section{Synthetic procedures}

Large scale synthesis of $M I L-100(A l)$ !! Caution !! This synthesis employs large amounts of chemicals, therefore precautions must be taken. This is especially the case for the dissolution of aluminium chloride in water, which is extremely exothermic and may release hydrogen chloride. 
Therefore, this dissolution must be performed under an efficient fumehood using good quality borosilicate, thickwalled, glassware. Water must be poured as quickly as possible on $\mathrm{AlCl}_{3}$ to avoid overheating. This step causes impressive and excessive fuming. Preparation of solution A: $31.5 \mathrm{~g}$ of trimesic acid were dissolved in $3 \mathrm{~L}$ of denaturated ethanol in a $4 \mathrm{~L}$ Erlenmeyer flask. The flask was shaken until all the acid was completely dissolved. Stepwise addition of the acid and sonication are recommended for avoiding the formation of aggregates and speeding up the process. Once a clear solution was obtained, $3.15 \mathrm{ml}$ of concentrated hydrochloric acid were added and the mixture was homogenised by shaking. Preparation of solution $B: 17.25 \mathrm{~g}$ of $\mathrm{AlCl}_{3}$ were added in a dry $4 \mathrm{~L}$ Erlenmeyer flask. $3 \mathrm{~L}$ of demineralized water was added through a large glass funnel, the first $1000 \mathrm{ml}$ were added as fast as possible (!! Exothermic reaction !!). The mixture was homogenised, followed by the addition of $35.0 \mathrm{ml}$ of DMF. The flask was shaken to obtain a homogeneous mixture. Preparation of the MOF: Solutions $\mathrm{A}$ and $\mathrm{B}$ were mixed together in a $10 \mathrm{~L}$ polyethylene can. The can was closed with a screw cap and thoroughly shaken to obtain a homogeneous mixture. The mixture was then poured in glass bottles (10 bottles of $500 \mathrm{ml}$ capacity each containing $400 \mathrm{ml}$ of the reaction mixture, and 1 bottle of $2.5 \mathrm{~L}$ capacity containing $2000 \mathrm{ml}$ of the mixture). All the bottles were placed into an oven at $83^{\circ} \mathrm{C}$ for 6 days. The white precipitate was centrifuged at $6000 \mathrm{rpm}$ and washed with water ( 3 times) and ethanol (3 times). The powder was then suspended in a minimum amount of ethanol and the suspension was evaporated under reduced pressure at $70^{\circ} \mathrm{C}$ using a rotary evaporator.

Small-scale syntheses of Al-BTC MOFs: Solutions A and $B$ were prepared as described above (in smaller volumes). $200 \mathrm{ml}$ of each solution were then mixed together in 500 $\mathrm{ml}$ screw-capped glass bottles. The bottles were sealed and placed in an oven at $80^{\circ} \mathrm{C}$ for a given amount of time $(4,5$, $6,8,11$ or 15 days). The white precipitate was centrifuged at $4000 \mathrm{rpm}$ and washed with water (3 times) and ethanol (3 times). The powder was then suspended in a minimum amount of ethanol and the liquid was evaporated under reduced pressure at $70^{\circ} \mathrm{C}$ using a rotary evaporator. !!! Note that the rotation speed during the centrifugation is lower than for the large-scale synthesis (the speed for the largescale synthesis was increased in order to recover more material). This has two consequences on the obtained product: 1 . More material is recovered (the supernatants are not clear solutions, but have an aspect similar to milk); 2 . The size distribution of the particles changes when higher speeds are used; this can be seen by broadening of the PXRD peaks and on the BJH pore size distribution of the materials. The presence of very small (nano)-particles is in agreement with the aspect of the supernatants.

Functionalization with ethylenediamine: The following procedure was adapted from an earlier report describing the synthesis of EN@MIL-10o(Cr).31.2 g of as-synthesized MIL-10o were introduced into a $250 \mathrm{ml}$ three-neck flask equipped with a condenser, a rubber septum and a glass stopcock. The MOF was heated at $200^{\circ} \mathrm{C}$ under vacuum (using the glass stopcock connected to a Schlenk line) overnight for activation. The flask was subsequently allowed to cool down under vacuum and the stopcock was closed. Then, $120 \mathrm{ml}$ of anhydrous toluene were added by using a syringe. Once the toluene was added, the flask was backfilled with argon. Note: adding the toluene when the flask is under vacuum allows to wet the MOF powder so that it does not fly up in the flask when the volume is backfilled with argon. The suspension was stirred to disperse the MOF and $0.10 \mathrm{ml}$ of ethylenediamine were added by syringe. The stopcock was closed again and an argon filled balloon was added at the top of the condenser. The mixture was then refluxed for $12 \mathrm{~h}$. After cooling down the flask, the mixture was centrifuged and the toluene supernatant discarded. The solid was then washed 3 times with $n$-hexane and 2 times with n-pentane. The obtained solid was then dried, while still being in the (open) centrifugation tubes, in an oven under air at $45^{\circ} \mathrm{C}$ during 3 hours to afford a powder of the functionalized MOF (white powder for EN@MIL-10o(Al); brown powders for EN@MIL-10o(Fe) and EN@MIL-10o(Fe,Al)).

Synthesis of the 8-thiomethyl-BODIPY fluorescent dye: The BODIPY dye was synthesized according to a reported three-step procedure, ${ }^{4}$ with small modifications. In brief, a solution of freshly distilled pyrrole $(4.2 \mathrm{ml}$ in $90 \mathrm{ml}$ of dry ether) was added dropwise to a thiophosgene solution (2.3 $\mathrm{ml}$ in $8 \mathrm{o} \mathrm{ml}$ of dry toluene) in an ice bath $\left(\mathrm{o}^{\circ} \mathrm{C}\right)$ under argon by using a syringe. After complete addition, the solution was stirred for 30 minutes. The reaction was then quenched by addition of $100 \mathrm{ml}$ of a $10 \mathrm{~mol} \% \mathrm{NaOH}$ solution in water/methanol (10:90 v/v), followed by one hour of stirring at room temperature. The solvent was then removed in vacuo and the resulting crude product was purified on a short silica pad by using a heptane/DCM (1:3 v/v) mixture containing $1 \%$ triethylamine. Only the bright orange fraction was collected and the solvents evaporated in vacuo, yielding red crystals of high purity of Bis-( $1 \mathrm{H}-$ pyrrol2-yl)-methione. ${ }^{1} \mathrm{H}-\mathrm{NMR}\left(\mathrm{CDCl}_{3}, 300 \mathrm{MHz},{ }_{2} 23 \mathrm{~K}\right): \delta 7.8 \mathrm{o}$ $(2 \mathrm{H}, \mathrm{m}), 7.42(2 \mathrm{H}, \mathrm{m}), 6.53-6.54(2 \mathrm{H}, \mathrm{m}), 2.91(3 \mathrm{H}, \mathrm{s})) .0 .45 \mathrm{~g}$ of the obtained product was subsequently dissolved in 7.4 $\mathrm{ml}$ of DCM under argon atmosphere, followed by the addition of $2.9 \mathrm{ml}$ of methyl iodide. The mixture was stirred for $26 \mathrm{~h}$ at room temperature and the solvent was evaporated in vacuo. The obtained crude 2-[Methylsulfanyl-( $1 \mathrm{H}-\mathrm{pyr}-$ rol-2-yl)-methylene]-2H-pyrrolium iodide was used for the last step of the synthesis without further purification or analysis. $0.88 \mathrm{~g}$ of the obtained product was dissolved in 19 $\mathrm{ml}$ of DCM under argon atmosphere, followed by the addition of $2 \mathrm{ml}$ of triethylamine and subsequent stirring at room temperature for $40 \mathrm{~min}$. Then, $1.63 \mathrm{ml}$ of $\mathrm{BF}_{3} \cdot \mathrm{Et}_{2} \mathrm{O}$ was added and the mixture stirred further for $24 \mathrm{~h}$. Solvent were removed in vacuo and the obtained crude product was dissolved in some DCM. The product was purified by chromatography on silica by subsequently using heptane/DCM/triethylamine mixtures with various solvents ratios (100:10:1.1 $\rightarrow$ 100:100:2 $\rightarrow$ 50:100:1.5). A second purification, consisting in washing in water and extraction in toluene allowed to obtain high purity 8-(Thiomethyl)4,4difluoro-4-bora-3a,4a-diaza-sindacene (BODIPY). 
Post-functionalisation with BODIPY dye: $50 \mathrm{mg}$ of MOF sample were soaked in $15 \mathrm{ml}$ of a solution of the BODIPY probe in dichloromethane $(1 \mathrm{mg}$ in $100 \mathrm{ml})$ and stirred for 10 minutes before being filtered and washed with dichloromethane on a PTFE filtration membrane (pore size $0.45 \mu \mathrm{m}$ ). The BODIPY functionalized samples were finally air dried.

\section{Ninhydrin and bromothymol blue tests}

Ninhydrin test: First, a solution of $5 \cdot 10^{-3} \mathrm{M}$ of ninhydrin in ethanol was prepared. Then, a calibration plot was determined with hexylamine as a standard primary amine. A specific amount of hexylamine solution (between $5 \cdot 10^{-5}$ and $8.3 \cdot 10^{-4} \mathrm{M}$ ) was mixed with ninhydrin for $2 \mathrm{~h}$ at $65^{\circ} \mathrm{C}$, then cooled for $15 \mathrm{~min}$ at room temperature. The primary amine peak appears at $580 \mathrm{~nm}$ (blue coloration). MOF suspensions of $0.5 \mathrm{~g} / \mathrm{L}$ were prepared in ethanol and dispersed for 5 min under ultrasonic treatment. Then, $2 \mathrm{~mL}$ of these suspensions were mixed with $1 \mathrm{~mL}$ of the ninhydrin solution for $2 \mathrm{~h}$ under $65^{\circ} \mathrm{C}$ and cooled at room temperature for 15 min. The samples were centrifuged at 15,0oo RPM for 30 min. Then, the supernatants were measured with the spectrophotometer and the concentration of primary amine was estimated thanks to absorbance measured at $580 \mathrm{~nm}$ and the calibration plot.

Acidity determination by adsorption of bromothymol blue: A transparent solution of bromothymol blue in toluene was prepared (50 $\mathrm{mg}$ in $100 \mathrm{ml}$ ) and about $10 \mathrm{ml}$ of this solution was added to 50-100 mg of sample of the solid to be analyzed in a test tube. The solution was stirred with a glass rod until the sample was colored (about $1 \mathrm{~min}$ ). Then the solid was decanted, toluene was removed by using a pipette and the sample was washed twice with $n$-hexane and once with $n$-pentane, followed by drying in a vacuum oven at $60^{\circ} \mathrm{C}$ for about $30 \mathrm{~min}$. The diffuse reflectance spectra of the obtained samples were then measured.

\section{Results and discussion}

Collapse of $M I L-100(F e)$ upon contact with ethylenediamine

Our first attempt concerned the functionalization with ethylenediamine of MIL-10o(Fe), which was obtained using a previously described method ${ }^{21}$. To do so, the synthesized MOF was first activated by heating under vacuum at $200^{\circ} \mathrm{C}$ to remove physisorbed and coordinated solvent molecules, and was then refluxed under argon in toluene in the presence of EN. However, the powder X-ray diffraction (PXRD) pattern of MIL-10o(Fe) after this treatment revealed that the compound had completely lost its crystallinity, becoming amorphous (see ESI, Fig. S1). Significant changes were also observed in the FTIR spectrum of MIL$100(\mathrm{Fe})$ after the reaction with EN (see ESI, Fig. S2). This shows that MIL-10o(Fe) cannot be functionalized with ethylenediamine without collapsing, unlike the more robust MIL-100(Cr)..$^{14,15}$

\section{Optimised synthesis of MIL-10o(Al)}

Regarding MIL-10o(Al), most reports on the synthesis of this particular MOF use hydro- or solvothermal processes involving high reaction temperatures. ${ }^{22,23,24}$ We thus attempted an approach using a lower temperature, set at $80^{\circ} \mathrm{C}$. We obtained the Al-based MOF by mixing an ethanol solution containing trimesic acid and some $\mathrm{HCl}$ with an aqueous solution of $\mathrm{AlCl}_{3}$ containing some DMF (see Experimental section for details). The obtained mixture was incubated in closed screw-capped glass bottles in an oven at $80^{\circ} \mathrm{C}$ and the resulting white precipitates were washed with water and ethanol and collected by centrifugation followed by drying under vacuum.
A.

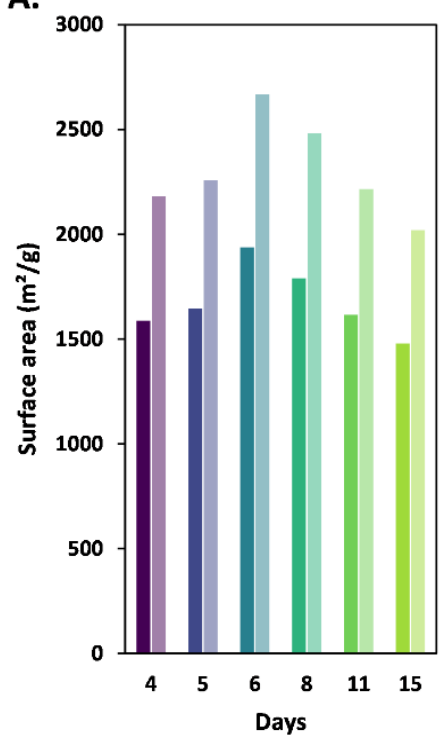

B.

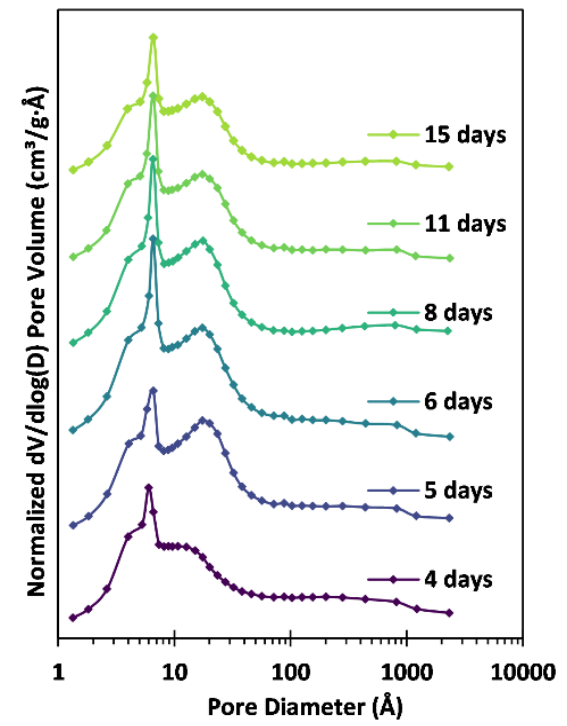

C.

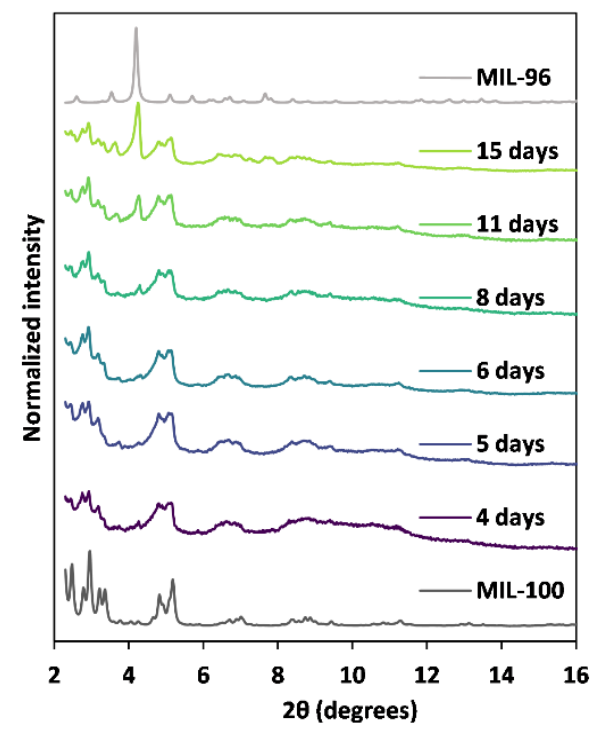

Figure 1. A. Evolution of the Brunauer-Emmett-Teller (dark colours) and Langmuir (light colours) surface areas of Al-BTC MOF samples obtained after different reaction times. B. Evolution of the Barrett-Joyner-Halenda pore size distribution of Al-BTC MOF samples obtained after different reaction times. C. PXRD patterns of Al-BTC MOF samples obtained after different reaction times, along with simulated patterns of MIL-10o and MIL-96 for comparison (wavelength: $1.5406 \AA$ ). 
Nitrogen sorption experiments were performed on MOF samples obtained after different incubation times to evaluate their specific surface area by the Brunauer-EmmettTeller (BET) and Langmuir methods (Figure 1, A) as well as their Barrett-Joyner-Halenda (BJH) pore size distribution (Figure 1, B). From the obtained results, it is clear that a maximum in surface area is obtained after 6 days of reaction $\left(\mathrm{S}_{\mathrm{BET}}=1937 \mathrm{~m}^{2} / \mathrm{g}\right)$; longer reaction times leading to a continuous decrease of surface areas. Overall, all the MOF samples obtained have quite large surface areas: between 1479 and $1937 \mathrm{~m}^{2} / \mathrm{g}$ (BET), or 2019 and $2667 \mathrm{~m}^{2} / \mathrm{g}$ (Langmuir) (Figure 1, A).

To determine why the evolution of the surface area went through a maximum, powder X-ray diffraction (PXRD) patterns of all samples were measured after activation by heating under vacuum at $200^{\circ} \mathrm{C}$ for 10 hours (Figure $1, \mathrm{C}$ ). The MOFs obtained after 4, 5 and 6 days of reaction time show the presence of a pure MIL-10o phase whereas the samples isolated after longer reaction times also contain MIL-96 as a secondary phase. MIL-96 is another Al-BTC MOF having lower surface area than MIL-10o, ${ }^{25,26}$ thus explaining why it decreases after 6 days of reaction. The formation of MIL-96 upon longer reaction times can be explained by its better thermodynamic stability. ${ }^{23}$ The presence of unreacted trimesic acid in the pores of the compounds, which is commonly encountered when other preparation methods are used, can be excluded according to the FTIR spectra of the different samples (Figure 2, A and Fig. $\left.\mathrm{S}_{3}\right)$, as the characteristic bands of $\mathrm{C}=\mathrm{O}\left(1720 \mathrm{~cm}^{-1}\right)$ and $\mathrm{C}-\mathrm{O}\left(1349\right.$ and $1273 \mathrm{~cm}^{-1}$ ) stretching of free $\mathrm{H}_{3}$ BTC are not present. ${ }^{27}$ The increase of surface area between 4 to 6 days of reaction is presumably due to the slow formation and crystallization of MIL-10o, leading to the highest quality MIL-10o(Al) sample after 6 days.

To our delight, the BJH pore size distribution plots show the presence of not only micropores in the materials, but also small mesopores with a diameter of around $20 \AA$ (Figure 1, B). The presence of such mesopores would not be expected based on the crystal structures of MIL-10o or MIL-96, which are both microporous and should give rise to a type I isotherm. Furthermore, the nitrogen sorption isotherms displayed a hysteresis (see ESI, Fig. $\mathrm{S}_{4}$ and $\mathrm{S}_{5}$ ), which is not what would be expected for microporous compounds. ${ }^{28}$ This led to the conclusion that the obtained materials possess hierarchized porosity. This is a useful textural feature because large pores are of interest to keep large surface areas upon functionalization of MOFs, and hierarchized solids allow faster diffusion of guest molecules through the porous framework. ${ }^{29}$ The analysis of the $\mathrm{BJH}$ plots shows that there is also an optimum of the pore size distribution after 6 days of reaction.

Given the interesting textural properties of the obtained MIL-10o(Al) MOF, we decided to investigate the possibility to scale-up the synthesis. For this purpose, several litres of precursor solution were prepared (see Experimental section for the detailed procedure) and several grams of MOF were successfully obtained by applying the optimized reaction conditions. The scaled-up sample was characterized and showed good phase purity (see ESI) and was thus used for further experiments.

Successful functionalisation of Al-containing MIL-10o with EN

To perform functionalization with $\mathrm{EN}$, the sample was activated in vacuum at $200^{\circ} \mathrm{C}$ and then reacted with ethylenediamine in refluxing anhydrous toluene. The sample was then isolated by centrifugation, washed with hexane and pentane and dried in air at $45^{\circ} \mathrm{C}$ to yield EN@MIL-10o(Al). The obtained powder was characterized by PXRD (ESI, Fig. S1), showing that the structure did not undergo collapse during the functionalization procedure, by opposition to MIL-10o(Fe). Aluminium-based MIL-10o, unlike its $\mathrm{Fe}$ analogue, is thus resistant enough to retain its structure upon reaction with EN. This shows that the choice of the metal composing the MOF, rather than the MOF's structure, is of critical importance for achieving efficient grafting of EN. Interestingly, a bimetallic MIL$100(\mathrm{Fe}, \mathrm{Al})$ MOF (which's synthesis is described elsewhere), ${ }^{21}$ characterized by a $\mathrm{Fe} / \mathrm{Al}$ ratio of about $80 / 20$, resists the same treatment with ethylenediamine, showing that $\mathrm{Al}$ stabilizes the structure, even when present in rather low concentrations in the MOF (see ESI for more details, Fig. S1, Fig. S2 and Fig. S1o). Thermogravimetric analysis (TGA) (ESI, Fig. S1o) of EN@MIL-10o(Al) showed a decomposition temperature very close to the one of pristine MIL$100(\mathrm{Al})\left(-430^{\circ} \mathrm{C}\right)$. A rather continuous weight loss, attributed to guest species (i.e. EN and solvent molecules), is taking place before decomposition.

The nitrogen sorption isotherms of EN@MIL-10o(Al) after activation at $150^{\circ} \mathrm{C}$ (ESI, Fig. Si1) revealed a BET surface area decrease from $1861 \mathrm{~m}^{2} / \mathrm{g}$ for pristine MIL-10o(Al) to $657 \mathrm{~m}^{2} / \mathrm{g}$ upon functionalization, owing to the EN molecules partly occupying the volume of the pores.

The effectiveness of the grafting on MIL-10o(Al) was evidenced by the FTIR spectrum (Figure 2, A), presenting characteristic absorption bands expected for ethylenediamine grafting, especially visible at $1370 \mathrm{~cm}^{-1}$. The presence of EN in the MOF was further confirmed by solution-state ${ }^{1} \mathrm{H}$ NMR experiments on the digested MOF (details about ${ }^{1} \mathrm{H}$ NMR analysis and reference sample measurements can be found in the Experimental section and ESI, Fig. S12). The spectrum of activated MIL-100(Al) presents a singlet at 8.14 ppm, corresponding to the aromatic signals of the trimesate ligand, whereas the spectrum of digested EN@MIL$100(\mathrm{Al})$ shows the same peak (downshifted to $8.28 \mathrm{ppm}$, due to differences in $\mathrm{D}_{2} \mathrm{SO}_{4}$ concentration of the solution) and a supplementary singlet at $2.90 \mathrm{ppm}$, unambiguously demonstrating the presence of ethylenediamine. The ratio of the integrals of the peaks of the aromatic protons of the ligand and the protons of EN allowed us to determine the number of EN molecules per cluster (Figure 2, B and C; see also ESI for details on calculations based on the MOF's structure). The as-synthesized sample achieved $\mathbf{1 . 2}$ EN/cluster on average. A portion of the sample was heated under vacuum to remove physisorbed EN and was subsequently digested for ${ }^{1} \mathrm{H}$ NMR analysis. As expected, the amount of EN decreased somewhat when the sample was 
A.

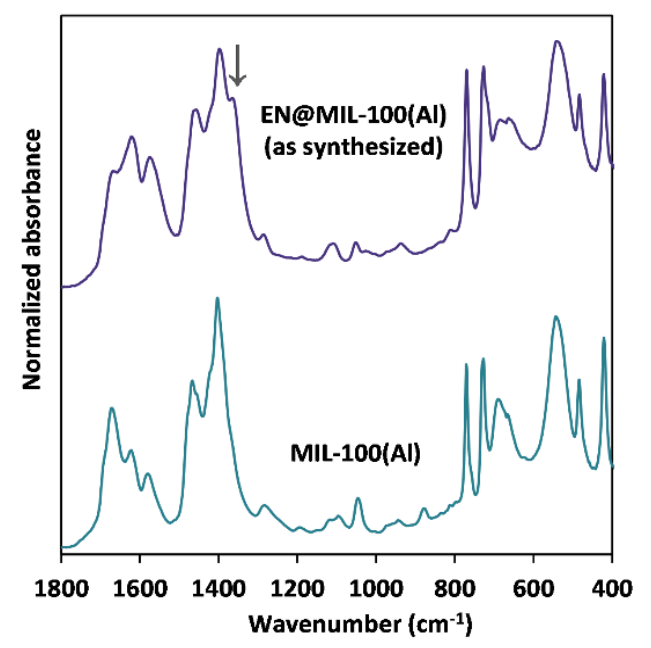

B.

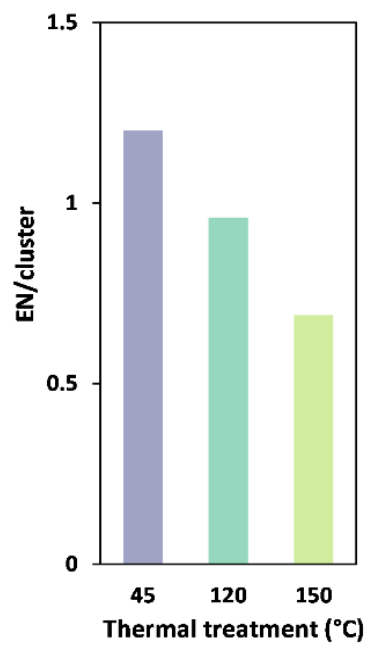

C.

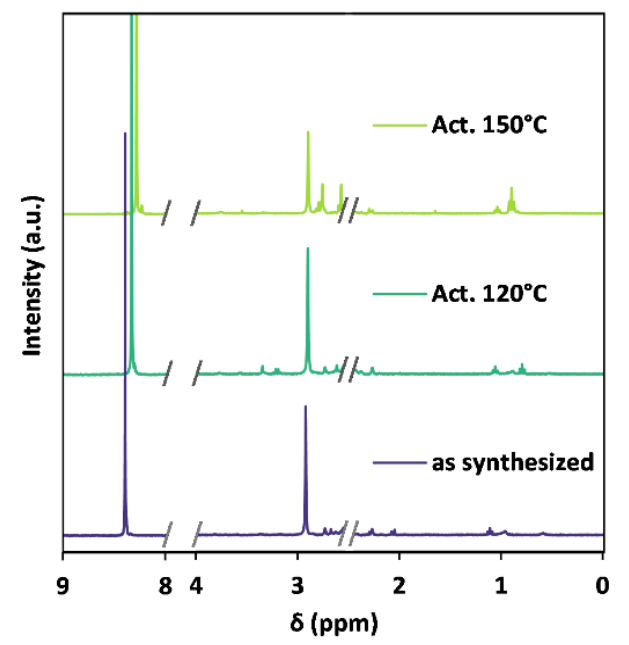

Figure 2. A. FTIR spectra of as-synthesized MIL-10o(Al) and EN@MIL-10o(Al) MOFs. B. EN/cluster ratios calculated from integration of ligand and ethylenediamine peaks in ${ }^{1} \mathrm{H}-\mathrm{NMR}$ spectra of digested EN@MIL-10o(Al) samples treated at different temperatures $\left(45^{\circ} \mathrm{C}=\right.$ as synthesized sample, $120^{\circ} \mathrm{C}$ and $150^{\circ} \mathrm{C}$ were heated under vacuum). C. Solution-state ${ }^{1} \mathrm{H}-\mathrm{NMR}$ spectra of as-synthesized and activated EN@MIL-10o(Al) digested samples.

heated to $120^{\circ} \mathrm{C}$, to reach $0.96 \mathrm{EN} /$ cluster on average. Heating to $150^{\circ} \mathrm{C}$ however led to a decomposition of part of the EN present in the pores (see ESI, Fig. S12, for detailed NMR spectra). Our results show that about one out of three $\mathrm{Al}$ sites is occupied by EN, which is in agreement with previous reports stating that only one $\mathrm{Al}$ per cluster can be coordinatively unsaturated by activation under vacuum, ${ }^{27}$ and thus accept an EN molecule.

The grafting of EN was also evidenced by solid-state NMR CP-MAS experiments. ${ }^{13} \mathrm{C}$ spectra of MIL-10o(Al) show signals around 170 and $130 \mathrm{ppm}$ for the carboxylate and aromatic carbons, respectively. ${ }^{27}$ Upon EN addition a separated signal around $38 \mathrm{ppm}$ is clearly observed due to the aliphatic chain of the added ligand (Figure 3, A). Besides that, ${ }^{15} \mathrm{~N}$ solid state NMR spectrum (Figure 3, B) shows the presence of two signals of comparable intensities at 25 and $31 \mathrm{ppm}$, upshifted with respect to liquid (neat) EN (17.8 ppm, not shown). These results indicate that the two nitrogen atoms experience similar environment, in agreement with the results reported in the literature $^{30}$ and the EN grafting model we propose (see inset of Figure 3, B) with one Al-coordinated nitrogen atom and one free amine group. Signals of the ${ }^{27} \mathrm{Al}$ spectra of both pristine and functionalized MOFs (Fig. S13) present a chemical shift around o ppm, similar to previously reported spectra of hydrated MIL-10o(Al), ${ }^{27}$ confirming that the metallic centres are six-coordinated. Furthermore, after functionalization with $\mathrm{EN}$, the resulting signal possesses a more important downfield contribution, which can be explained by an increased p character of the Al-N bond of the metal centre with the amine compared to the Al-O bonds with the oxo-, hydroxo- and carboxylate ligands. ${ }^{31,32}$
A.

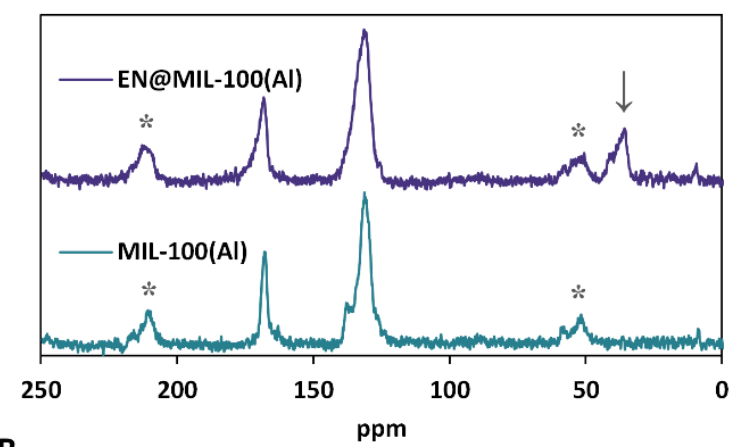

B.

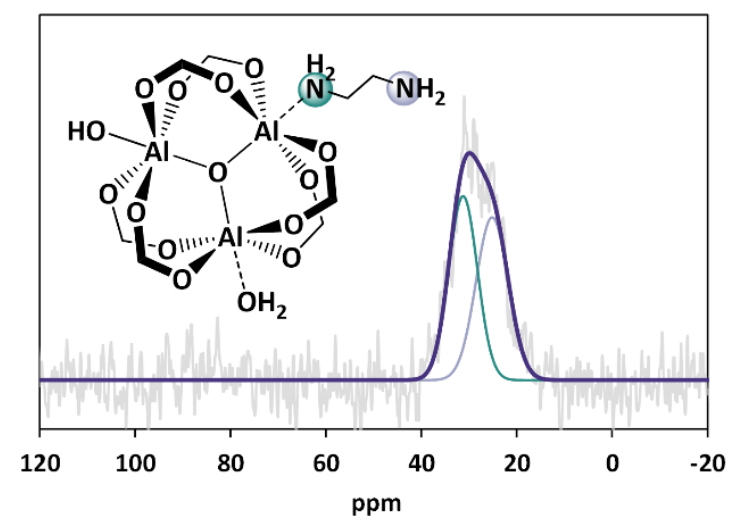

Figure 3. A. ${ }^{13} \mathrm{C}$ CPMAS NMR spectra of MIL-10o(Al) after activation at $200^{\circ} \mathrm{C}$ and of as-synthesized EN@MIL-10o(Al). B. ${ }^{15} \mathrm{~N}$ CPMAS spectrum of EN@MIL-10o(Al) with deconvolution of the peak. The inset is the determined structure of the functionalized cluster units of EN@MIL-10o(Al). Asterisks indicate spinning sidebands. 


\section{Availability of pending amines}

The possibility of performing post-functionalization of the pending amine sites in the EN@MIL-10o(Al) material was investigated. This was performed by using 8-thiomethyl-BODIPY (Figure 4, A). This fluorescent molecule specifically reacts with primary amines, inducing the formation of linked 8-amino-BODIPY (Figure 4, B), shifting the emission maximum of the free dye from $525 \mathrm{~nm}$ (green) to $409-427 \mathrm{~nm}$ (blue), allowing to visually determining whether the reaction occurred. ${ }^{33,34}$ To do this, both pristine and ethylenediamine functionalized MIL-10o(Al) were soaked in a dichloromethane solution of 8-thiomethylBODIPY and were then recovered by filtration. After this treatment, the pristine MOF showed a green fluorescence (Figure 4, A), which is typical of the unreacted BODIPY probe, indicating that the molecule was only non-specifically adsorbed onto the MOF's surface and in into its pores. In contrast, the EN@MIL-10o(Al) sample showed the specific blue fluorescence of the bonded BODIPY fluorophore (Figure 4, B), indicating that the post-functionalization reaction was performed successfully.
A.

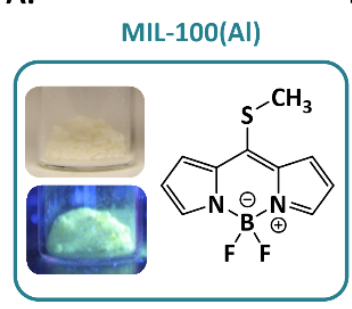

C.

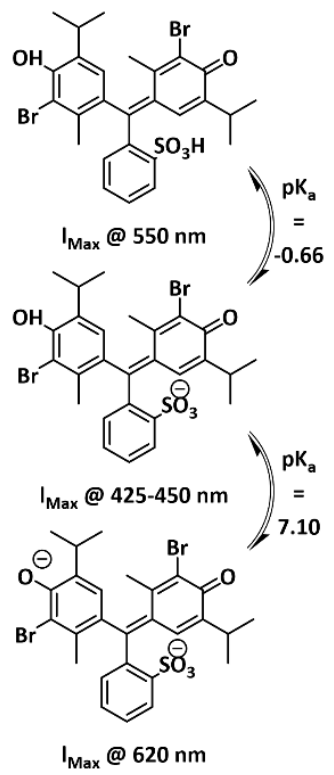

B.

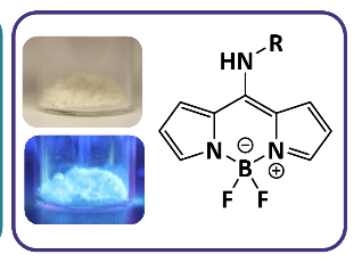

D.

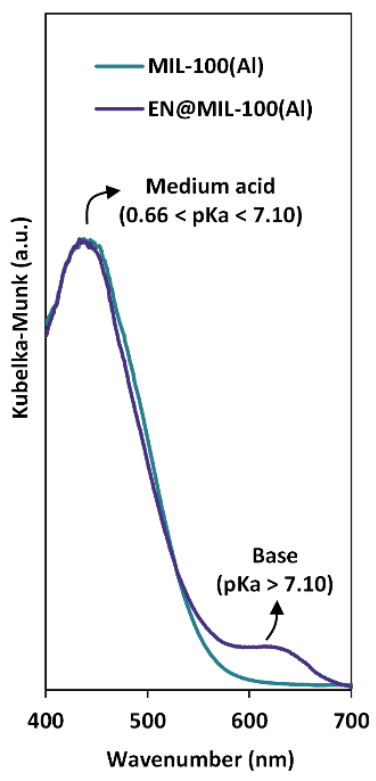

Figure 4. A. and B. Photographs under (upper) visible light and (lower) UV irradiation of (A) MIL-10o(Al) and (B) EN@MIL-10o(Al) after post-functionalization with 8-thiomethyl-BODIPY, with structures of the unreacted 8-thiomethylBODIPY and the 8-amino-BODIPY grafted upon reaction. C. Structure of bromothymol blue under different protonation states. D. Diffuse-reflectance UV-vis spectra of BTB impregnated MIL-100(Al) and EN@MIL-10o(Al).

The degree of availability of the amine functions was evaluated by reaction with ninhydrin in hot ethanol. Ninhydrin specifically reacts to form a blue dye, 2-(1,3-dioxoindan-2-yl)iminoindane-1,3-dione, that is liberated in solution after its formation. The quantitative analysis of the dye content in the supernatant solution after centrifugal separation of the MOF allows determining the amount of amines that reacted with ninhydrin. ${ }^{35}$ The UV-vis spectrum of the supernatant solution after reaction with ninhydrin revealed that reaction with primary amines occurred, as indicated by the typical absorption band at $580 \mathrm{~nm}$ (ESI, Fig. S14). Quantitative analysis however revealed that only o.6 mmol of $-\mathrm{NH}_{2}$ functions reacted per gram of MOF. This is less than the quantity of free amine functions determined by solution-state ${ }^{1} \mathrm{H}$ NMR on the digested EN@MIL-10o(Al) sample $\left(\sim 1.65 \mathrm{mmol} . \mathrm{g}^{-1}\right.$, or one free $-\mathrm{NH}_{2}$ per $\mathrm{Al}_{3} \mathrm{O}$ trimer $)$. This might be explained by the microporous windows of MIL-10o(Al), which are narrowed by the presence of ethylenediamine, and are too small to allow for optimal diffusion of ninhydrin inside the material and for optimal release of the formed 2-(1,3-dioxoindan-2-yl)iminoindane1,3-dione out of the material. Therefore, it is expected that efficient post-functionalization of all the $-\mathrm{NH}_{2}$ functions of the material would only be possible with molecules that are small enough.

\section{Brønsted acido-basicity of EN@MIL-10o(Al)}

It has previously been evidenced that MIL-10o(Al) possesses a strong Brønsted acidity due to the presence of water coordinated to the aluminium. ${ }^{36}$ We assumed that EN@MIL-10o(Al) should possess both, Brønsted acidic sites due to the water molecule, and Brønsted basic sites due to the presence of $-\mathrm{NH}_{2}$ functions. We decided to investigate this by a method inspired by the one of Hammett, which uses coloured $\mathrm{pH}$ indicators to probe the strength of acid sites on colourless solids. 37 Our method relies on the use of bromothymol blue (BTB), which is fairly soluble in toluene. We used several solids which are known for their strong $\left(\mathrm{H}_{3} \mathrm{PMo}_{12} \mathrm{O}_{40}\right.$ and ZSM-5 zeolite) or medium (chromatography silica gel and $\mathrm{UiO}-66(\mathrm{Zr}) \mathrm{MOF}$ ) Brønsted acidity, their strong basicity $\left(\mathrm{NaAlO}_{2}, \mathrm{Al}_{2} \mathrm{O}_{3}, \mathrm{MgO}\right)$, as well as mixtures thereof $\left(\mathrm{SiO}_{2} / \mathrm{Al}_{2} \mathrm{O}_{3}\right.$ in various ratios $)$ as reference materials (see ESI, Fig. S15). In practice, the solids are immersed in the BTB solution and are repeatedly washed with toluene and alkanes before being dried and analysed by diffuse reflectance UV-vis. The absorption spectra of the resulting powders is indicative of the surface Brønsted acidity of the materials, given by an absorption maximum around $550 \mathrm{~nm}$ for strong acids (pKa <-o.66), 425-450 nm for medium acids $(0.66<\mathrm{pKa}<7.10)$ and $620 \mathrm{~nm}$ for bases ( $\mathrm{pKa}>7.10$ ), resulting from the different protonation states of indicator molecule (Figure $4, \mathbf{C}$ ). This experiment shows that the Brønsted acidic sites in MIL-10o( $\mathrm{Al})$ are medium acids (pKa comprised between -0.66 and 7.10) and that acidic sites of similar strength are present in the ethylenediamine functionalized sample (Figure 4, D). The experiment also confirms that additionally to those acidic sites, EN@MIL-10o $(\mathrm{Al})$ possesses basic sites with a $\mathrm{pKa}>7.10$ due 
to the presence of amines, imparting both Brønsted acidity and basicity to this material. The crystallinity of the materials was checked after impregnation with bromothymol blue (see ESI, Fig. S14). Interestingly, crystallinity was maintained for MIL-10o(Al), whereas the long range order EN@MIL-10o(Al) was clearly disrupted after impregnation. Such long range order disturbance has previously been observed in MIL-10o(Al) upon adsorption of other dyes such as methylene blue, Coomassie brilliant blue G-250 and rhodamine B. ${ }^{8}$

\section{Carbon dioxide sorption}

The adsorption of carbon dioxide in both pristine and functionalized MOFs was studied by means of gravimetric methods at a pressure of $1 \mathrm{~atm}$ and by volumetric methods at higher pressures. Gravimetric adsorption measurements were performed on a thermogravimetric system in which the samples were first heated at $100^{\circ} \mathrm{C}$ under helium atmosphere to remove physisorbed species but avoiding removing the grafted ethylenediamine. The samples were then cooled down to room temperature and three adsorption/desorption cycles were performed by switching the working gas from helium to $\mathrm{CO}_{2}$. The obtained results are shown in the ESI (Fig. S17). The obtained results are indicative of the $\mathrm{CO}_{2}$ sorption kinetics of the materials, as well as their sorption capacity. Concerning the pristine MOFs, MIL-10o(Fe) is able to adsorb slightly more carbon dioxide than the aluminium-containing materials. The iron-based MOF also reaches full capacity faster than the two other pristine MOFs. Upon functionalization with EN, MIL-10o(Fe) however loses its ability to adsorb $\mathrm{CO}_{2}$, which was expected based on the amorphous nature of the material that was revealed by PXRD. EN@MIL-10o(Al) adsorbs less $\mathrm{CO}_{2}$ than its non-functionalized counterpart, which can be explained by its lower surface area (smaller free volume of the pores). The bimetallic MOF however retains most of its adsorption capacity after functionalization, allowing slightly more $\mathrm{CO}_{2}$ to be adsorbed in EN@MIL-10o(Fe,Al) than in EN@MIL-10o(Al).

Volumetric measurements were performed for the pristine and functionalized Al-MOF activated at $100^{\circ} \mathrm{C}$ (Figure 5, A). As can be expected based on the respective surface areas of MIL-10o(Al) and EN@MIL-10o(Al), the EN functionalized material adsorbs about $60 \%$ less $\mathrm{CO}_{2}$ than its non-functionalized counterpart. Surprisingly, both MIL-10o(Al) and EN@MIL-10o(Al) show a non-classical sorption behaviour. Both materials adsorb the gas in an expected manner up to a pressure of 25 bar, pressure at which a slowing down of the uptake kinetics and an unexpected increase in the excess uptake are observed. Furthermore, a hysteresis is observed upon desorption for both samples. The measurements were shown to be repeatable, if the material was kept for sufficient time under high vacuum between two adsorption cycles. To rule out that this phenomenon might be the result of residual solvents in the pores, MIL-10o(Al) was activated at $200^{\circ} \mathrm{C}$ and a second measurement was performed (Figure 5, B). The activation at higher temperature resulted in negligibly higher excess uptake but the overall sorption behaviour remained unchanged.
We hypothesize that a reaction with the un-removable water molecule coordinated to the $\mathrm{Al}_{3} \mathrm{O}$ clusters is responsible of this unique sorption behaviour, probably by formation of a carbonic acid species at high pressure:

$\mathrm{Al}-\mathrm{OH}_{2}+\mathrm{CO}_{2} \rightarrow \mathrm{Al}-\mathrm{H}_{2} \mathrm{CO}_{3}$

Volumetric adsorption was also performed on MIL-10o(Fe) (Figure 5, B), as this material is known to lose all its coordinated water molecules upon activation. The resulting isotherm revealed a perfectly reversible, "classical", sorption behaviour of the material, confirming that the unique adsorption behaviour of EN-functionalized and pristine MIL-10o(Al) is due to the nature of the metal, and likely to the coordinated water.

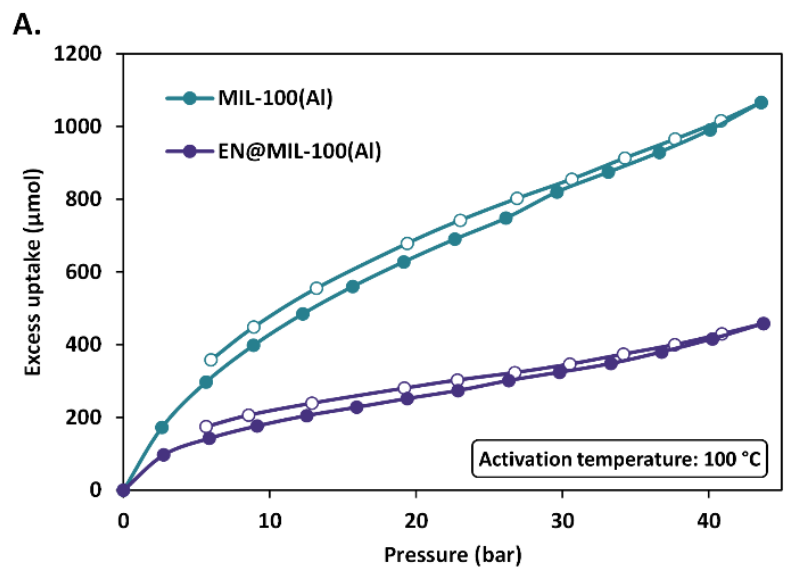

B.

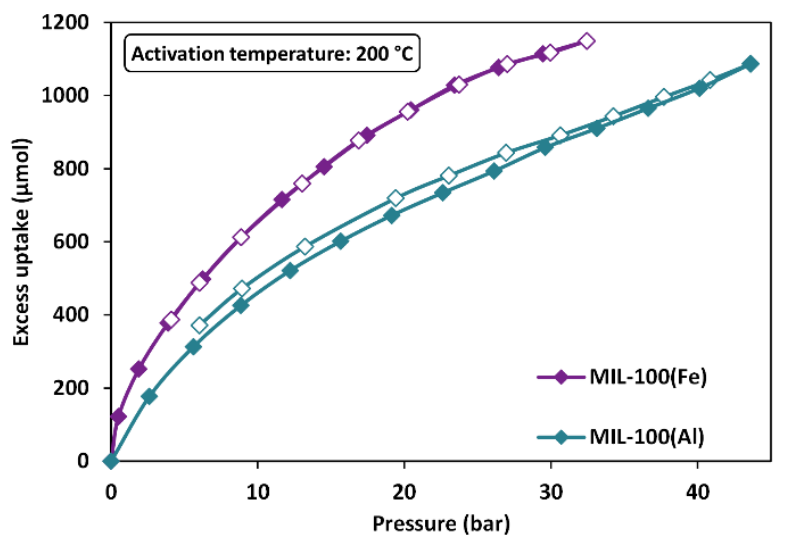

Figure 5. A. $\mathrm{CO}_{2}$ uptake isotherms of MIL-10o(Al) and EN@MIL-10o(Al) activated at $100^{\circ} \mathrm{C}$ and B. MIL-10o(Fe) and MIL-10o(Al) activated at $200^{\circ} \mathrm{C}$.

\section{Conclusions}

We performed functionalization of the metal sites of two distinct monometallic $\mathrm{Fe}$ and $\mathrm{Al}$ MOFs from the MIL-10o series with ethylenediamine. The second MOF, MIL$100(\mathrm{Al})$, was obtained in mild conditions as a hierarchically structured solid with micro- and mesopores, free of unreacted trimesic acid, through a new procedure. Our experiments showed that only MIL-10o(Al) was strong enough to retain its crystallinity upon reaction with EN, whereas MIL-10o(Fe) collapsed. These results demonstrate that the 
choice of the metal composing the MOF's structure is of critical importance for the successful functionalization of the metal centres in MOFs rather than the MOF structure. The efficient incorporation of EN in the MOF was demonstrated by an original approach based on solution NMR, allowing to evidence and quantify the presence of the complete EN molecule, which is not possible by using elemental analysis. Solid-state NMR further confirmed that the grafted EN possesses one free $-\mathrm{NH}_{2}$ that adds new functionality to the MOF. The stabilizing role of aluminium in the framework was further demonstrated by reacting $\mathrm{EN}$ with a mixed-metal MIL-10o( $\mathrm{Fe}, \mathrm{Al})(\mathrm{Fe} / \mathrm{Al}=8 \mathrm{o} / 20)$ MOF, which preserved its crystalline state. The obtained materials are promising for post-functionalization through amine chemistry, as demonstrated by the successful reaction with 8-thiomethyl-BODIPY and ninhydrin. Interestingly, EN@MIL-10o(Al) possesses both Brønsted acidic and basic sites, as demonstrated by a colorimetric approach based on bromothymol blue adsorption, opening the door to applications such as bifunctional acid/base catalysis. The ethylenediamine-functionalized MOFs show lower gravimetric and volumetric $\mathrm{CO}_{2}$ uptakes than their pristine counterparts due to the space occupied by the EN molecules. Finally, we evidenced the unique $\mathrm{CO}_{2}$ adsorption behaviour of aluminium-based MIL-10o and its ENfunctionalized counterpart, revealing sorption isotherms with hysteretic behaviour, which is unique among the MOFs of the MIL-10o family.

\section{ASSOCIATED CONTENT}

Supporting Information. PXRD patterns, FTIR spectra, nitrogen adsorption isotherms, TGA curves and NMR spectra of the pristine and functionalized MOFs, diffuse reflectance spectra of bromothymol blue adsorbed MOFs and gravimetric $\mathrm{CO} 2$ sorption curves.

\section{AUTHOR INFORMATION}

\section{Corresponding Authors}

Timothy Steenhaut - Institute of Condensed Matter and Nanosciences, UCLouvain, Louvain-la-Neuve, Belgium

Yaroslav Filinchuk - Institute of Condensed Matter and Nanosciences, UCLouvain, Louvain-la-Neuve, Belgium

Sophie Hermans - Institute of Condensed Matter and Nanosciences, UCLouvain, Louvain-la-Neuve, Belgium

\section{Author Contributions}

The manuscript was written through contributions of all authors. All authors have given approval to the final version of the manuscript.

\section{Funding Sources}

The authors acknowledge the F.R.S./FNRS for the FRIA fellowship of T.S. and for the grant CdR J.oo73.20.

Notes

The authors declare no competing financial interest.

\section{ACKNOWLEDGMENT}

The authors acknowledge Dr. François Devred for supplying the reference samples for the bromothymol blue acidity test.

\section{REFERENCES}

(1) Senkovska, I.; Barea, E.; Navarro, J. A. R.; Kaskel, S. Adsorptive Capturing and Storing Greenhouse Gases Such as Sulfur Hexafluoride and Carbon Tetrafluoride Using MetalOrganic Frameworks. Microporous Mesoporous Mater. 2012, 156, 115-120. https://doi.org/10.1016/j.micromeso.2012.02.021.

(2) Sumida, K.; Rogow, D. L.; Mason, J. A.; McDonald, T. M.; Bloch, E. D.; Herm, Z. R.; Bae, T. H.; Long, J. R. Carbon Dioxide Capture in Metal-Organic Frameworks. Chem. Rev. 2012, 112 (2), 724-781. https://doi.org/10.1021/cr2003272.

(3) Li, H.; Wang, K.; Sun, Y.; Lollar, C. T.; Li, J.; Zhou, H. C. Recent Advances in Gas Storage and Separation Using MetalOrganic Frameworks. Mater. Today 2018, 21 (2), 108-121. https://doi.org/10.1016/j.mattod.2017.07.0o6.

(4) Wu, M. X.; Yang, Y. W. Metal-Organic Framework (MOF)-Based Drug/Cargo Delivery and Cancer Therapy. Adv. $\begin{array}{llll}\text { Mater. } & 2017 & 29 & \text { (23), }\end{array}$ https://doi.org/10.1002/adma.201606134.

(5) Liu, Y.; Xie, X. Y.; Cheng, C.; Shao, Z. S.; Wang, H. S. Strategies to Fabricate Metal-Organic Framework (MOF)-Based Luminescent Sensing Platforms. J. Mater. Chem. C 2019, 7 (35), 10743-10763. https://doi.org/10.1039/c9tc03208h.

(6) Wang, H. H.; Shi, W. J.; Hou, L.; Li, G. P.; Zhu, Z.; Wang, Y. Y. A Cationic MOF with High Uptake and Selectivity for $\mathrm{CO}_{2}$ Due to Multiple CO2-Philic Sites. Chem. - A Eur. J. 2015, 21 (46), 16525-16531. https://doi.org/10.1002/chem.201502532.

(7) Vaidhyanathan, R.; Iremonger, S. S.; Dawson, K. W.; Shimizu, G. K. H. An Amine-Functionalized Metal Organic Framework for Preferential CO 2 Adsorption at Low Pressures. Chem. Commun. 2009, No. 35, 5230-5232. https://doi.org/10.1039/b911481e.

(8) Ma, W.; Xu, L.; Li, Z.; Sun, Y.; Bai, Y.; Liu, H. PostSynthetic Modification of an Amino-Functionalized MetalOrganic Framework for Highly Efficient Enrichment of N-Linked Glycopeptides. Nanoscale 2016, 8 (21), 10908-10912. https://doi.org/10.1039/c6nro249od.

(9) Lin, Y.; Kong, C.; Chen, L. Amine-Functionalized MetalOrganic Frameworks: Structure, Synthesis and Applications. RSC $\begin{array}{llll}A d v & 2016, & 6 & \text { (39), }\end{array}$ https://doi.org/10.1039/c6rao1536k.

(10) Montoro, C.; García, E.; Calero, S.; Pérez-Fernández, M. A.; López, A. L.; Barea, E.; Navarro, J. A. R. Functionalisation of MOF Open Metal Sites with Pendant Amines for $\mathrm{CO}_{2}$ Capture. J. $\begin{array}{lllll}\text { Mater. } & \text { Chem. 2012, } & 22 & \text { (20), } & 10155-10158 .\end{array}$ https://doi.org/10.1039/c2jm1677ok.

(11) Wang, N.; Mundstock, A.; Liu, Y.; Huang, A.; Caro, J. Amine-Modified Mg-MOF-74/CPO-27-Mg Membrane with Enhanced $\mathrm{H}_{2} / \mathrm{CO}_{2}$ Separation. Chem. Eng. Sci. 2015, 124, 27-36. https://doi.org/10.1016/j.ces.2014.10.037.

(12) Zhong, R.; Yu, X.; Meng, W.; Han, S.; Liu, J.; Ye, Y.; Sun, C.; Chen, G.; Zou, R. A Solvent 'Squeezing' Strategy to Graft Ethylenediamine on $\mathrm{Cu}_{3}(\mathrm{BTC})_{2}$ for Highly Efficient $\mathrm{CO}_{2} / \mathrm{CO}$ Separation. Chem. Eng. Sci. 2018, 184, 85-92. https://doi.org/10.1016/j.ces.2017.12.040.

(13) Yeon, J. S.; Lee, W. R.; Kim, N. W.; Jo, H.; Lee, H.; Song, J. H.; Lim, K. S.; Kang, D. W.; Seo, J. G.; Moon, D.; Wiers, B.; Hong, C. S. Homodiamine-Functionalized Metal-Organic Frameworks with a MOF-74-Type Extended Structure for Superior Selectivity of $\mathrm{CO}_{2}$ over N2. J. Mater. Chem. A 2015, 3 (37), 19177-19185. https://doi.org/10.1039/c5tao2357b.

(14) Cabello, C. P.; Berlier, G.; Magnacca, G.; Rumori, P.; Palomino, G. T. Enhanced $\mathrm{CO}_{2}$ Adsorption Capacity of AmineFunctionalized MIL-10o(Cr) Metal-Organic Frameworks. 
$\begin{array}{lllll}\text { CrystEngComm } & \mathbf{2 0 1 5}, & 17 & \text { (2), } & 430-437 .\end{array}$ https://doi.org/10.1039/c4ceo1265h.

(15) Wang, L.; Zhang, F.; Wang, C.; Li, Y.; Yang, J.; Li, L.; Li, J. Ethylenediamine-Functionalized Metal Organic Frameworks MIL-10o(Cr) for Efficient $\mathrm{CO}_{2} / \mathrm{N}_{2} \mathrm{O}$ Separation. Sep. Purif. Technol. 2020, 235 (October 2019), 116219. https://doi.org/10.1016/j.seppur.2019.116219.

(16) Sepehrmansouri, H.; Zarei, M.; Ali, M. Multilinker Phosphorous Acid Anchored En / MIL-10o ( $\mathrm{Cr}$ ) as a Novel Nanoporous Catalyst for the Synthesis of New N -Heterocyclic Pyrimido [ 4 , 5- b ] Quinolines. Mol. Catal. 2019, No. October 2018, 1-17. https://doi.org/10.1016/j.mcat.2019.01.023.

(17) Pertiwi, R.; Oozeerally, R.; Burnett, D. L.; Chamberlain, T. W.; Cherkasov, N.; Walker, M.; Kashtiban, R. J.; Krisnandi, Y. K.; Degirmenci, V.; Walton, R. I. Replacement of Chromium by Non-Toxic Metals in Lewis-Acid MOFs: Assessment of Stability as Glucose Conversion Catalysts. Catalysts 2019, 9 (437). https://doi.org/10.3390/catal9050437.

(18) Bartlett, L.; Vesilind, P. A. Chemistry and Controversy: The Regulation of Environmental Chromium. Environ. Eng. Policy 1998, 1 (2), 81-86. https://doi.org/10.1007/s1002200500o8.

(19) Férey, G.; Serre, C.; Mellot-Draznieks, C.; Millange, F.; Surblé, S.; Dutour, J.; Margiolaki, I. A Hybrid Solid with Giant Pores Prepared by a Combination of Targeted Chemistry, Simulation, and Powder Diffraction. Angew. Chemie - Int. Ed. 2004, 43 (46), 6296-6301. https://doi.org/10.1002/anie.200460592.

(20) Horcajada, P.; Surble, S.; Serre, C.; Hong, D.; Seo, Y.; Chang, J.; Grene, J. Synthesis and Catalytic Properties of MIL-10o ( Fe ), an Iron ( III ) Carboxylate with Large Pores. Chem. Comm. 2007, 100, 2820-2822. https://doi.org/10.1039/b704325b.

(21) Steenhaut, T.; Hermans, S.; Filinchuk, Y. Green Synthesis of a Large Series of Bimetallic MIL-10o(Fe,M) MOFs. New J. Chem. 2020, 44, 3847-3855. https://doi.org/10.1039/donjoo257g.

(22) Seoane, B.; Dikhtiarenko, A.; Mayoral, A.; Tellez, C.; Coronas, J.; Kapteijn, F.; Gascon, J. Metal Organic Framework Synthesis in the Presence of Surfactants: Towards Hierarchical MOFs? CrystEngComm 2015, $17 \quad$ (7), $1693-1700$. https://doi.org/10.1039/c4ceo2324b.

(23) Qiu, M.; Guan, Q.; Li, W. Controllable Assembly of AlMIL-10o via an Inducing Occupied Effect and Its Selective Adsorption Activity. Cryst. Growth Des. 2016, 16 (7), 3639-3646. https://doi.org/10.1021/acs.cgd.6boo103.

(24) Yang, J.; Wang, J.; Deng, S.; Li, J. Improved Synthesis of Trigone Trimer Cluster Metal Organic Framework MIL-10oAl by a Later Entry of Methyl Groups. Chem. Commun. 2016, 52 (4), 725728. https://doi.org/10.1039/c5cco845od.

(25) Benzaqui, M.; Pillai, R. S.; Sabetghadam, A.; Benoit, V.; Normand, P.; Marrot, J.; Menguy, N.; Montero, D.; Shepard, W.; Tissot, A.; Martineau-Corcos, C.; Sicard, C.; Mihaylov, M.; Carn, F.; Beurroies, I.; Llewellyn, P. L.; De Weireld, G.; Hadjiivanov, K.; Gascon, J.; Kapteijn, F.; Maurin, G.; Steunou, N.; Serre, C. Revisiting the Aluminum Trimesate-Based MOF (MIL-96): From Structure Determination to the Processing of Mixed Matrix Membranes for $\mathrm{CO}_{2}$ Capture. Chem. Mater. 2017, 29 (24), 1032610338. https://doi.org/10.1021/acs.chemmater.7bo3203.

(26) Loiseau, T.; Volkringer, C.; Haouas, M.; Taulelle, F.; Férey, G. Crystal Chemistry of Aluminium Carboxylates: From Molecular Species towards Porous Infinite Three-Dimensional
Networks. Comptes Rendus Chim. 2015, 18 (12), 1350-1369. https://doi.org/10.1016/j.crci.2015.08.oo6.

(27) Haouas, M.; Volkringer, C.; Loiseau, T.; Férey, G.; Taulelle, F. Monitoring the Activation Process of the Giant Pore MIL-10o(Al) by Solid State NMR. J. Phys. Chem. C 2011, 115 (36), 17934-17944. https://doi.org/10.1021/jp206513v.

(28) Thommes, M.; Kaneko, K.; Neimark, A. V.; Olivier, J. P.; Rodriguez-Reinoso, F.; Rouquerol, J.; Sing, K. S. W. Physisorption of Gases, with Special Reference to the Evaluation of Surface Area and Pore Size Distribution (IUPAC Technical Report). Pure Appl. Chem. 2015, 87 (9-10), 1051-1069. https://doi.org/10.1515/pac-20141117.

(29) Koo, J.; Hwang, I. C.; Yu, X.; Saha, S.; Kim, Y.; Kim, K. Hollowing out MOFs: Hierarchical Micro- and Mesoporous MOFs with Tailorable Porosity via Selective Acid Etching. Chem. Sci. 2017, 8 (10), 6799-6803. https://doi.org/10.1039/c7sc02886e.

(30) Jaźwiński, J.; Kamieński, B.; Sadlej, A. Polymeric Adducts of Rhodium(II) Tetraacetate with Aliphatic Diamines: Natural Abundance ${ }_{13} \mathrm{C}$ and ${ }_{15} \mathrm{~N}$ CPMAS NMR Investigations. Magn. Reson. Chem. 2013, $51 \quad$ (12), 788-794. https://doi.org/10.1002/mrc.4017.

(31) Martineau, C.; Taulelle, F.; Haouas, M. The Use of $27 \mathrm{Al}$ NMR to Study Aluminum Compounds: A Survey of the Last 25 Years. In The Chemistry of Organoaluminum Compounds (PATAI'S Chemistry of Functional Groups); Micouin, L., Marek, I., Rappoport, Z., Eds.; John Wiley \& Sons, Ltd.: Chichester, 2016; pp 1-51. https://doi.org/10.1002/9780470682531.pato840.

(32) Smith, M. E. Application Of27Al NMR Techniques to Structure Determination in Solids. Appl. Magn. Reson. 1993, 4 (12), 1-64. https://doi.org/10.1007/BFo3162555.

(33) Kim, D.; Yamamoto, K.; Ahn, K. H. A BODIPY-Based Reactive Probe for Ratiometric Fluorescence Sensing of Mercury Ions. Tetrahedron 2012, 68 (26), 5279-5282. https://doi.org/10.1016/j.tet.2012.01.091.

(34) Kim, D.; Ma, D.; Kim, M.; Jung, Y.; Kim, N. H.; Lee, C.; Cho, S. W.; Park, S.; Huh, Y.; Jung, J.; Ahn, K. H. Fluorescent Labeling of Protein Using Blue-Emitting 8-Amino-BODIPY Derivatives. J. Fluoresc. 2017, 27 (6), 2231-2238. https://doi.org/10.1007/s10895-017-2164-5.

(35) Soto-Cantu, E.; Cueto, R.; Koch, J.; Russo, P. S. Synthesis and Rapid Characterization of Amine-Functionalized Silica. Langmuir 2012, $28 \quad$ (13), $\quad$ 5562-5569. https://doi.org/10.1021/la204981b.

(36) Volkringer, C.; Leclerc, H.; Lavalley, J. C.; Loiseau, T.; Férey, G.; Daturi, M.; Vimont, A. Infrared Spectroscopy Investigation of the Acid Sites in the Metal-Organic Framework Aluminum Trimesate MIL-10o(Al). J. Phys. Chem. C 2012, 116 (9), 5710-5719. https://doi.org/10.1021/jp210671t.

(37) Lyle, S. J.; Flaig, R. W.; Cordova, K. E.; Yaghi, O. M. Facilitating Laboratory Research Experience Using Reticular Chemistry. J. Chem. Educ. 2018, 95 (9), 1512-1519. https://doi.org/10.1021/acs.jchemed.8boo265.

(38) Cai, J.; Mao, X.; Song, W. G. Adsorption Behavior and Structure Transformation of Mesoporous Metal-Organic Frameworks towards Arsenates and Organic Pollutants in Aqueous Solution. Mater. Chem. Front. 2018, 2 (7), 1389-1396. https://doi.org/10.1039/c8qmoooo2f. 


\section{EN@MIL-100(M)}

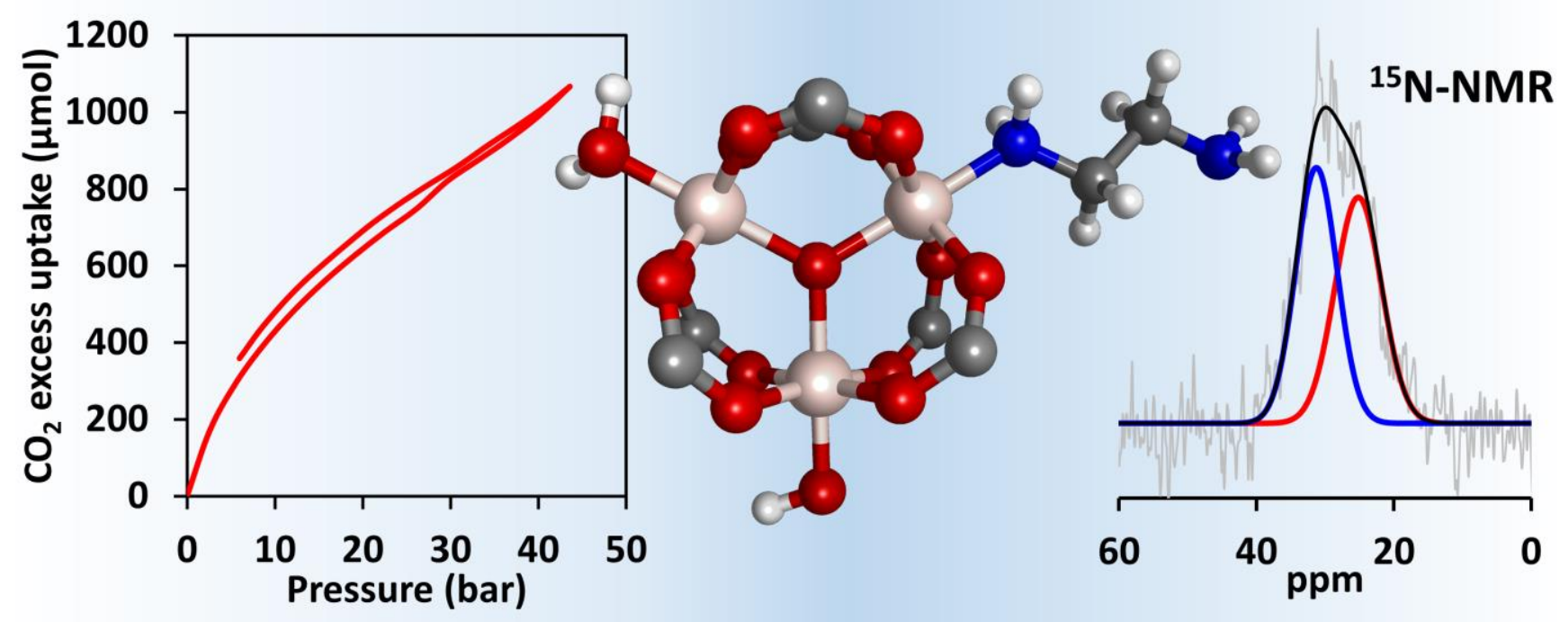

